\title{
Testing of Continuous Sampling Air-ICP and Mercury Systems as Continuous Emission Monitors at the Diagnostic Instrumentation and Analysis Laboratory
}

September 18-26, 2000

D. P. Baldwin, S. J. Bajic, D. E. Eckels, and D. S. Zamzow, Ames Laboratory, and G. P. Miller, S. Tao, and C. A. Waggoner, DIAL

Ames Laboratory-USDOE

Report IS-5144

February 15, 2001

Revised, March 15, 2001 


\section{Introduction}

This report has been prepared to document the performance of the continuous sampling reduced-pressure air-ICP-AES (inductively coupled plasma - atomic emission spectroscopy) and mercury-monitor systems developed by Ames Laboratory for use as continuous emission monitors (CEM). This work was funded by the U. S. Department of Energy, Office of Environmental Management, Office of Science and Technology, through the Mixed Waste Focus Area. The purpose of the project is to develop instrumentation and methods for spectroscopic field monitoring applications. During FY00 this included continued work on the development of the continuous sample introduction system and the multi-frequency AOTF-echelle spectrometer, used in conjunction with the reduced-pressure air-ICP-AES system as a multi-metal CEM. The assembly, development, and testing of an echelle spectrometer system for the detection of mercury $(\mathrm{Hg})$ by atomic absorption was also completed during FY00. The continuous sampling system and the multi-metal air-ICP and mercury-monitor CEM systems were tested at Mississippi State University at the Diagnostic Instrumentation and Analysis Laboratory (DIAL) at the end of FY00. This report describes the characteristics and performance of these systems, and the results of the field tests performed at DIAL.

The continuous sampling air-ICP and mercury-monitor CEM systems are being developed in response to the need of DOE and other organizations to monitor the heavy-metal or radioactive materials that may be released during the processing or combustion of hazardous or mixed-waste materials. The air-ICP system has been designed for the on-line detection and monitoring of heavy metals (beryllium, cadmium, chromium, and lead, in particular) in process or exhaust gas streams by optical emission spectroscopy. Due to the relatively poor limits of detection for $\mathrm{Hg}$ by optical emission techniques, the mercury-monitor CEM has been designed specifically for the detection of elemental $\mathrm{Hg}$ by optical absorption. A heated pyrolysis tube is used in this system to convert oxidized $\mathrm{Hg}$ compounds to elemental $\mathrm{Hg}$ prior to analysis, for the determination of total mercury in the gas sample stream. The promulgation of regulations limiting the release of these metals and requiring continuous monitoring of stack gases from combustion and treatment processes would seriously impact the operations of DOE waste incinerators and other facilities. Therefore, it is important to develop and validate techniques that adequately meet proposed sensitivity and accuracy requirements. The most likely form of validation for such a technique will involve comparison of CEM results for a test combustion 
system with EPA Reference Method 29 (RM-29). ${ }^{1}$ Therefore, the air-ICP and mercury-monitor CEM systems were tested at DIAL by monitoring metal emissions in a fuel oil-air combustion exhaust while simultaneously collecting samples using the RM-29 technique. The CEM results were available continuously during the on-line monitoring that was performed. The results of the RM-29 sampling were received a number of weeks after the testing at DIAL. These results are discussed in this report, with a comparison and evaluation of the RM-29 and air-ICP and mercury-monitor CEM data.

The continuous sampling reduced-pressure air-ICP-AES system was assembled and tested at Ames Laboratory during FY99, and a field test of the system was conducted at the end of FY99 at DIAL. The results for the FY99 test have been reported. ${ }^{2}$ For that test, the continuous sampling system and reduced-pressure air-ICP were connected to a sampling port on the DIAL "test-stand" (combustion system), and the system was operated as a CEM for metals analysis while simultaneously collecting samples using RM-29. Reasonable agreement between the continuous sampling air-ICP and RM-29 results were obtained for beryllium (Be), chromium $(\mathrm{Cr})$, and lead $(\mathrm{Pb})$ during the FY99 test, using the echelle spectrometer system. Due to a failure of the single-frequency AOTF in the AOTF-echelle spectrometer during the FY99 field test, these results were obtained using a $0.2-\mathrm{m}$ monochromator as a bandpass pre-filter for the echelle, rather than the AOTF. For the FY00 test at DIAL, a multi-frequency AOTF, capable of selecting three wavelength regions simultaneously to allow operation of the AOTF-echelle spectrometer as a simultaneous multi-metals CEM, was used. ${ }^{3}$ This was the first field test of the multi-frequency AOTF-echelle spectrometer. This spectrometer was used in conjunction with the reducedpressure air-ICP during the test at DIAL for simultaneous detection of the hazardous air pollutant metals $\mathrm{Be}$, cadmium $(\mathrm{Cd}), \mathrm{Cr}$, and $\mathrm{Pb}$. After the air-ICP CEM tests, the continuous sampling system was used in conjunction with the mercury-monitor system for the detection of $\mathrm{Hg}$. Laboratory testing of the mercury-monitor CEM system was conducted at Ames Laboratory during FY00, and the work performed at DIAL was the first field test of the mercury system. During the test at DIAL, RM-29 sampling was conducted concurrently with the operation of the air-ICP and mercury-monitor CEM systems, to allow a comparison of the reference method and CEM results. 


\section{Experimental}

\section{Continuous Sampling System}

A description of the continuous sampling system developed for this project has been published, ${ }^{2,3}$ and is only summarized here. A schematic diagram of the system is shown in Figure 1.

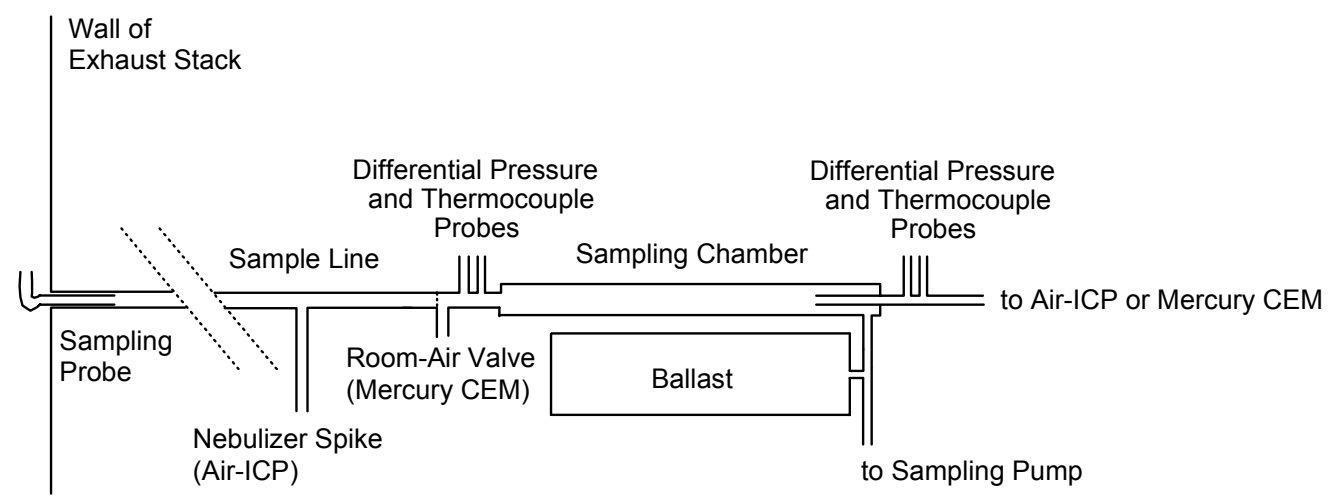

Figure 1. Schematic diagram of the continuous sampling system, with connection to an exhaust stack. Two heat-traced Teflon sample lines, one 12' and one 24' in length, were used to connect the sampling chamber to the sampling probe, inserted into the stack at DIAL.

The continuous sampling system is a dual-stage sampling system. A high-volume primary sample (20-30 standard liters per minute, Lpm) is drawn isokinetically from a process pipe or exhaust stack using a standard commercial EPA isokinetic glass-lined probe with an integral heater (Apex Instruments). The sampling probe is connected to a commercial heat-traced Teflon sample line (Technical Heaters), which is connected to the sampling chamber, a Teflon tube that is 1"-inner diameter and 24" in length. A rotary vane pump (Gast Manufacturing model 0523V4-G180DX) draws gas through the sampling chamber in a laminar-flow arrangement, with over $95 \%$ of the sample being removed through an exit port and exhaust line at the end of the chamber. On the inlet side of the sampling chamber, there are two ports (Teflon tees) that are provided for connecting a differential pressure transducer (Validyne model P55D) and a Tefloncoated thermocouple (Omega Engineering) to a Teflon differential pressure flow cell, so that the gas flow rate and temperature of the primary sample can be monitored. For the test at DIAL, a 30-standard-Lpm sample was drawn from the stack, using the sampling pump. Two heat-traced Teflon sample lines (attached in series for a total length of 36') were used to connect the sampling chamber (located inside the test facility at DIAL) to the stack sampling port (located outside). The sampling probe, sample lines, and sampling chamber were operated at 
approximately $110^{\circ} \mathrm{C}$ during the test at DIAL. To address the sample gas flow variations to the axial channel of the air-ICP observed during the FY99 test, resulting from pressure fluctuations in the exhaust line at DIAL, ${ }^{2}$ a ballast was added to the sampling system in FY00. The ballast is a 6"-inner diameter, 3.5'-long PVC chamber having an internal volume of approximately 19.5 L. The ballast is positioned next to the sampling chamber and connected to the exhaust line of the sampling chamber, which is connected to the sampling pump. The sample gas stream does not enter or flow through the ballast - only the exhaust line of the sampling chamber is connected to the ballast. This arrangement provides for a reduction in pressure variations in the sampling chamber resulting from pressure fluctuations in the stack, since the large-volume (19.5 L) ballast damps the variations in the smaller-volume (approximately $0.3 \mathrm{~L}$ ) sampling chamber. However, even with the addition of the ballast, apparent air-ICP axial channel gas flow fluctuations (and resulting ICP torch flicker) were observed during some of the FY00 air-ICP testing at DIAL, as discussed below. However, during testing of the mercury-monitor system, no significant flow fluctuations were observed at the gas flow gauge (oil-filled manometer) on the outlet side of the sampling chamber.

A secondary sample is drawn isokinetically from the gas flowing through the sampling chamber using a 1/4"-outer diameter Teflon sampling tube that is inserted approximately 4" into the end of the chamber. The tube currently used has a $0.170^{\prime \prime}$-inner diameter, with a $30^{\circ}$ taper at the sampling end. The secondary sample outlet is connected to a 1/4" Teflon Swagelok tee. The in-line port of this tee is followed by another Teflon differential pressure flow cell, to monitor the sample flow rate from the sampling chamber. A Teflon-coated thermocouple (Omega) is inserted into the inlet of this flow cell to measure the gas temperature. The differential pressure is monitored using an oil-filled manometer (Dwyer Instrument model 101) that has a maximum range of $0.5 "$ of water. The primary flow cell, Teflon sampling chamber, and secondary flow cell are heat-traced using electrical heat tape and insulation wrap. For the reduced-pressure airICP system, a rotary vane pump (Gast Manufacturing model 1023-101Q-G608X) is used to draw a slight vacuum on the ICP metal enclosure, drawing a sample flow of approximately 1 standard Lpm out of the sampling chamber, for introduction into the axial channel of the ICP. For the mercury-monitor system, a linear pump (Gast Manufacturing model SPP-6GAS-101) is used to draw a sample flow of approximately 1 standard Lpm from the sampling chamber, for introduction into a 1-m absorption cell. The secondary gas sample drawn from the sampling 
chamber is introduced into either the reduced-pressure air-ICP or the mercury-monitor system for the detection of hazardous air pollutant metals.

\section{Reduced-Pressure Air-ICP and Multi-Frequency AOTF-Echelle Spectrometer CEM}

The reduced-pressure air-ICP-AES system used for multi-metals emission monitoring has been described in detail previously, ${ }^{2,3}$ although some modifications have been made to the system. A photograph of the ICP metal enclosure is shown in Figure 2.

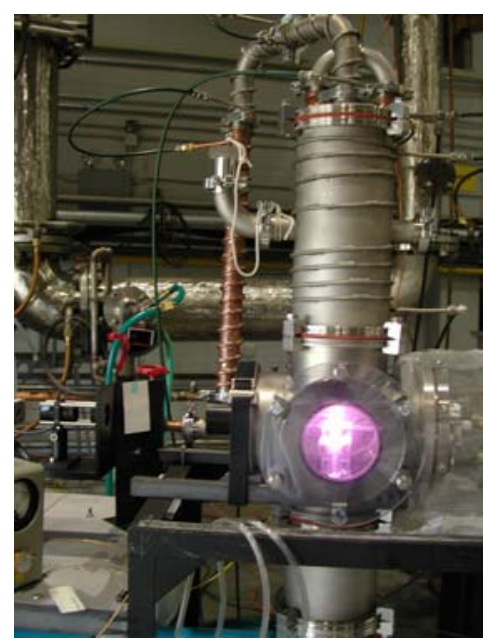

Figure 2. Photograph of the reduced-pressure air-ICP system, showing the air plasma inside the metal enclosure, part of the connection to the ICP auto-matching network (inside the wire mesh screen on the right), and the front-end of the AOTF-echelle spectrometer (on the left).

The system consists of an air-ICP that is operated at reduced pressure inside a 6"-diameter metal enclosure, the continuous sampling system, and the AOTF-echelle spectrometer. The bottom flange of the metal enclosure has gas-line connections for the ICP torch plasma and auxiliary gas supplies and for the ICP axial channel (sample) gas, which is connected to the Teflon sampling chamber. A connection point for the Tesla coil discharge required to ignite the ICP is included on the bottom flange of the enclosure. An additional gas-line connection on the bottom flange is provided for the introduction of supplemental air (approximately $50 \mathrm{Lpm}$ ), which provides some cooling of the metal enclosure during operation of the $3-\mathrm{kW}$ air plasma. Above the ICP torch, 1/4"-diameter stainless steel tubing is welded onto the 6"-diameter metal enclosure, for watercooling of the upper portion of the enclosure. At the top of the enclosure, 1.5"-diameter stainless steel and copper tubing is connected; water-cooling of this tubing is also provided to reduce the gas temperature of the ICP exhaust to less than $50^{\circ} \mathrm{C}$ prior to reaching the chamber pump. The chamber pump is connected to this 1.5 "-diameter tubing to operate the enclosure at reduced 
pressure, 0 to $-5 \mathrm{psig}$, in order to draw sample continuously into the plasma, from the Teflon sampling chamber, through the axial channel of the ICP torch. This pump has replaced the Roots blower, used in FY99, to decrease the overall size of the reduced-pressure air-ICP system. The ICP load coil (a 5-turn coil) is connected to the auto-matching network (Seren Industrial Power Systems solid-state, $27 \mathrm{MHz}$, 3-kW ICP system) using copper tubing feed-throughs in a Delrin flange on the right side of the metal enclosure. ${ }^{2,3}$ The plasma is generated using argon gas at approximately 1-kW RF power and then switched over to air operation, completely replacing the argon with air and increasing the RF power to approximately $3-\mathrm{kW}$.

Optical emission signals from metals introduced into the air-ICP are detected using the AOTF-echelle spectrometer. A 2"-diameter, 3" focal-length fused silica lens, mounted in the flange on the left side of the ICP enclosure, forms a 1:1 image of the plasma at the input aperture of the AOTF-echelle spectrometer. A quartz AOTF (MVM Electronics) placed between two crossed polarizers (Casix model PGT8208 $\alpha$-BBO Glan-Taylor polarizers) acts as an ordersorting pre-filter for the echelle. An RF frequency applied to the AOTF selects a narrow band (approximately 1-nm bandwidth) of optical emission from the ICP, which is introduced into the echelle. The bandpass of the AOTF is smaller than the width (free spectral range) of one order of the echelle grating, so no cross-dispersing optical element such as a prism or grating is required in the echelle spectrometer. This AOTF provides the capability of multi-wavelength simultaneous operation, since a multi-frequency RF driver is incorporated into the system. This allows for monitoring ICP emission signals from multiple elements simultaneously. The collimating and focusing mirrors in the current AOTF-echelle spectrometer are 0.4-m focallength off-axis parabolic mirrors (Atlantis Optical Laboratories, Inc.), not the 0.38-m focallength concave spherical mirrors used in the previous system. ${ }^{4}$ The detector is a two-stage thermoelectrically cooled CCD (Hamamatsu model S7032-1007).

For the test at DIAL, data acquisition for the metals $\mathrm{Be}, \mathrm{Cd}, \mathrm{Cr}$, and $\mathrm{Pb}$ was generally performed in a sequential, multi-element fashion, collecting data for $\mathrm{Be}$ and $\mathrm{Cr}$ in one data set and $\mathrm{Cd}$ and $\mathrm{Pb}$ in the following data set (switching the AOTF operating frequencies between data sets), at approximately 10 points per minute. Initial calibration of the air-ICP system was performed by introducing aqueous solution standards of metals $(\mathrm{Be}, \mathrm{Cd}, \mathrm{Cr}$, and $\mathrm{Pb}$ at varying concentrations) into a CETAC Technologies U5000-AT ultrasonic nebulizer (USN). The dry aerosol output from the USN was introduced into a tee on the inlet side of the 12' Teflon sample 
line connected to the sampling chamber (Nebulizer Spike in Figure 1), with one port of the tee open to room air. This arrangement was used for introducing metal aerosols into the sampling chamber and the air-ICP system for calibration and monitoring experiments with the stack not connected. After calibration, the system was connected to the stack at DIAL, for acquisition of stack-metals monitoring data. Since the USN was used for the introduction of metal aerosols into the stack, on-line metals standard additions, similar to those performed during the FY99 test, were not done. ${ }^{2}$ Instead, the response of the air-ICP AOTF-echelle system was checked at various intervals by comparing the calibration of the system against the initial non-stackconnected calibration curves.

\section{Mercury-Monitor CEM}

A mercury-monitor CEM system was assembled and tested during FY00 at Ames Laboratory and used for stack-mercury monitoring during the field test at DIAL. Elemental mercury is detected by atomic absorption in a 1-m pathlength absorption cell, using a mercury pen lamp as the source and a 0.38-m focal-length echelle spectrometer with a photodiode array (PDA) as the detector. This echelle spectrometer has no cross-dispersing optical element or order-sorting pre-filter, so all orders of the echelle grating are spatially superimposed at the detector. This spectrometer provides simultaneous detection of all of the strong $\mathrm{Hg}$ lines from 253-579 $\mathrm{nm}$ from the mercury pen lamp (diffracted from different orders of the echelle grating), without spectral overlap of these lines at the detector, as shown in Figure 3.

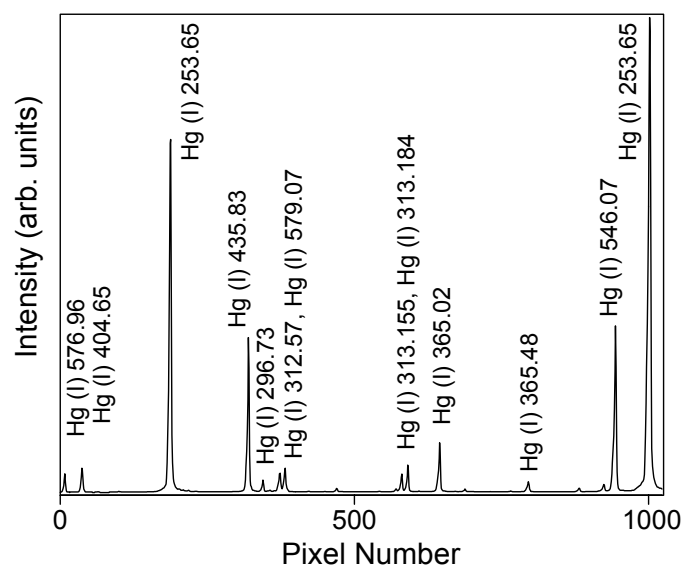

Figure 3. Mercury pen lamp spectrum, obtained using the Hg-echelle spectrometer.

The Hg (I) 253.65-nm line is used to measure absorption due to mercury in the 1-m cell. Other $\mathrm{Hg}$ lines (non-ground-state electronic transitions not subject to mercury absorption) can be used 
to correct for light source intensity fluctuations, light scattering by particles, and absorption due to species other than $\mathrm{Hg}$. Since all the mercury lines can be monitored simultaneously, this system in effect provides a dual-beam (or "multiple-beam") optical arrangement with a reference channel, using only a single light source, absorption cell, spectrometer, and detector. A schematic diagram and a photograph of the mercury-monitor CEM are shown in Figure 4.

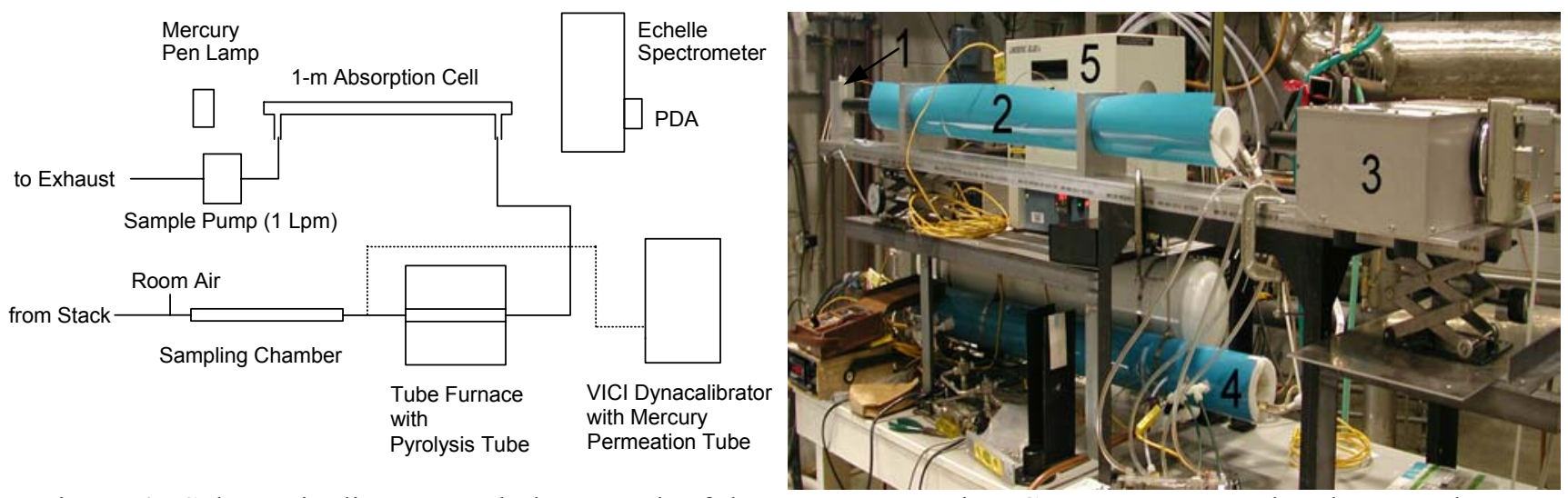

Figure 4. Schematic diagram and photograph of the mercury-monitor CEM system. In the photograph, the 1-m absorption cell is inside the 4'-long insulated tube (2), mounted on the metal frame, along with the mercury pen lamp (1, left side), optics, and $0.38-\mathrm{m}$ echelle spectrometer (3, right side) with PDA detector. The Teflon sampling chamber is inside the 4'-long insulated tube (4), on top of the table. The sample pump draws gas out of the sampling chamber, through the pyrolysis tube in the tube furnace (5), and through the absorption cell.

Light from a mercury pen lamp (Oriel model $6035 \mathrm{Hg}(\mathrm{Ar})$ lamp operated at 10-mA AC current, using an Oriel model 6060 power supply) is collected using a 1"-diameter, 6"-focal length fused silica lens, with the lamp emission approximately collimated through the 1-m absorption cell. The lamp is housed in an aluminum block, heated to $35^{\circ} \mathrm{C}$ using a cartridge heater (Omega Engineering model CIR-1031/120) and temperature controller (Valco Instruments model ITC10399). The absorption cell has quartz windows, and is heated to approximately $125^{\circ} \mathrm{C}$ using electrical heat tape inside an insulated tube (Accessible Products Company). Light that passes through the cell passes through BG-24A and WG-280 optical filters (Schott Glass Technologies - to attenuate the $\mathrm{Hg}$ (I) 253.65- and 546.07-nm lines with respect to the other $\mathrm{Hg}$ lines) prior to being focused onto the entrance slit of the echelle spectrometer, using a 1"diameter, 6"-focal length fused silica lens. This spectrometer is a modified version of the $0.38-\mathrm{m}$ echelle spectrometer described previously. ${ }^{4}$ The optics in this echelle consist of a 1"-diameter flat turning mirror, two 2"-diameter 0.38 -m focal-length concave spherical mirrors (Optics for Research) used as the collimating and focusing mirrors, the grating (Richardson Grating 
Laboratory model 35-13-19-417 echelle, 52.67 grooves per mm, $69^{\circ}$ blaze angle), and a 2"diameter flat turning mirror. The PDA is an EG\&G Princeton Applied Research model 1453 detector.

Sample stack gas is introduced into the mercury-monitor CEM using the continuous sampling system described above. A linear pump is used to draw a sample flow of approximately 1 standard Lpm from the Teflon sampling chamber, through a heated pyrolysis tube, and through the 1-m absorption cell. The pyrolysis tube is a 1"-diameter, 22"-long quartz tube, filled with 0.25 "-long quartz rings cut from 6-mm OD tubing, that is positioned inside the tube furnace (Lindberg/BlueM model TF55030A, operated at $1000^{\circ} \mathrm{C}$ ). The pyrolysis tube is used for thermal decomposition of oxidized $\mathrm{Hg}$ compounds to elemental $\mathrm{Hg}$, prior to introduction into the absorption cell. ${ }^{5,6}$ The $1 / 4$ "-OD Teflon tubing that connects the sampling chamber to the pyrolysis tube in the tube furnace and to the absorption cell is heat-traced using electrical heating tape and operated at approximately $60^{\circ} \mathrm{C}$. A two-way valve is inserted between the sample line and the sampling chamber (see Figure 1) to allow stack gas sampling or zero-checks to be performed. When performing zero-checks, room air (rather than stack gas) is drawn into the sampling chamber and the 1-m absorption cell, by valving off the sample stream from the combustion stack.

For the test at DIAL, mercury absorption was measured by ratioing the intensity for the $\mathrm{Hg}$ (I) 253.65-nm line to that for the Hg (I) 546.07-nm line. Absorption by elemental mercury vapor occurs at the $253.65-\mathrm{nm}$ line, but not at the $546.07-\mathrm{nm}$ line. Using both of these lines, an improvement in the accuracy and stability of the system is achieved, since short- and long-term fluctuations in the intensity output from the mercury lamp can be corrected for by using the intensity ratio. This detection scheme also corrects for light scatter from particles in the absorption cell, to the extent that this scattering is comparable at both 253.65 - and $546.07-\mathrm{nm}$. Prior to the introduction and analysis of the stack gas sample stream at DIAL, the mercurymonitor CEM was calibrated by measuring the absorption resulting from the introduction of 8.71 $\mu \mathrm{g} / \mathrm{m}^{3} \mathrm{Hg}$ into the $1-\mathrm{m}$ cell, from a permeation tube placed inside the Dynacalibrator (VICI model 340-55B-YD). Interference at $253.65-\mathrm{nm}$ due to absorption by sulfur dioxide $\left(\mathrm{SO}_{2}\right)$ in the stack gas sample was corrected during mercury-monitor data acquisition. The system was calibrated by introducing a known concentration of $\mathrm{SO}_{2}$ into the 1 - $\mathrm{m}$ cell (in the absence of $\mathrm{Hg}$ ) and measuring the absorption at 253.65 - and 313.18-nm, using the intensity ratios (253.65-to- 
546.07 and 313.18-to-546.07) for both of these lines. During stack sampling, a correction factor to the measured 253.65-nm absorption was applied, based on the measured 313.18-nm $\mathrm{SO}_{2}$ absorption, to remove the $253.65-\mathrm{nm} \mathrm{SO}_{2}$ absorption contribution. During the test at DIAL, $\mathrm{Hg}$ was introduced into the stack using the ultrasonic nebulizer (USN) at levels corresponding to approximately 80 and $8 \mu \mathrm{g} / \mathrm{m}^{3}$. Hydrogen chloride $(\mathrm{HCl})$ and $\mathrm{SO}_{2}$ gases were introduced at approximately 100 and $50 \mathrm{ppmV}$, respectively, during the high-level testing $\left(80 \mu \mathrm{g} / \mathrm{m}^{3} \mathrm{Hg}\right)$ and approximately 25 and $500 \mathrm{ppmV}$ during low-level testing $\left(8 \mu \mathrm{g} / \mathrm{m}^{3} \mathrm{Hg}\right)$. During the test at DIAL, mercury-monitor CEM data was acquired at a rate of approximately 20 points per minute.

\section{Results and Discussion}

\section{DIAL Stack Operating Conditions}

During FY00, the combustion test-stand at DIAL was modified by extending the exhaust line approximately ten meters, so that the RM-29 and CEM sampling ports were located outside the facility. This modification allowed the combustion furnace to be operated at its optimum conditions, rather than the fuel-lean conditions used in FY99 to minimize the gas temperature at the sampling ports. During the FY00 test, the furnace was operated with $500 \mathrm{lb} / \mathrm{hr}$ of air and 32 $\mathrm{lb} / \mathrm{hr}$ of fuel oil, which produced a gas flow in DIAL's 6"-diameter, schedule-80 pipe of approximately 4100 standard $\mathrm{Lpm}$. At the sampling point, the gas temperature was $150^{\circ} \mathrm{C}$, with a velocity of approximately $6.1 \mathrm{~m} / \mathrm{s}$. The CEM and RM-29 sampling probes were installed in a vertical section of the exhaust pipe, several meters downstream from the water-cooled exhaust line. The probes were inserted into the stack through opposing ports with the probe nozzles positioned in equivalent locations, within a few centimeters of each other (see Figure 5). This arrangement minimizes differences in stack metals concentrations introduced into the CEM and RM-29 systems. The equivalent nature of these opposing sampling positions has been demonstrated previously by simultaneous collection of two sets of RM-29 samples using two probes in this configuration. At the sampling point, the exhaust gas was flowing vertically down the pipe.

In FY00, the USN was used (rather than the pneumatic air-driven stack nebulizer used in FY99) for introducing appropriate concentrations of $\mathrm{Be}, \mathrm{Cd}, \mathrm{Cr}$, and $\mathrm{Pb}$ (air-ICP) and $\mathrm{Hg}$ (mercury-monitor CEM) into the exhaust stack gas. For the air-ICP testing, the USN output aerosol was introduced into the stack at a port approximately five meters upstream from the 
CEM and RM-29 sampling probes. For the mercury-monitor testing, the USN output aerosol was introduced into the stack afterburner, slightly more than one meter above the sampling port, so that the $\mathrm{Hg}$ in the aerosol would be vaporized and potentially oxidized after being introduced into the stack. During RM-29 sampling, the air-ICP or mercury-monitor CEM systems were used for on-line measurement of the stack-metals aerosol concentrations. The RM-29 collected samples were sent to an analytical testing laboratory for quantitative analysis.
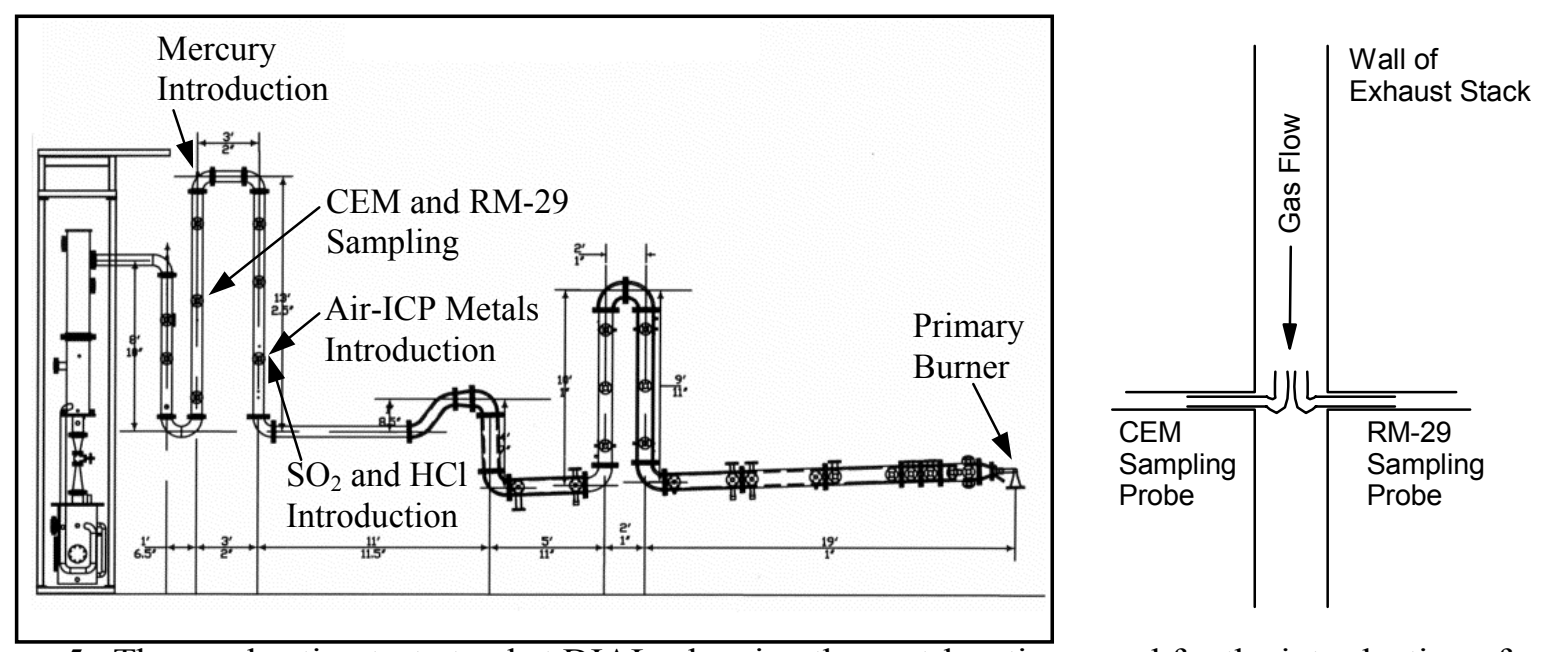

Figure 5. The combustion test-stand at DIAL, showing the port-locations used for the introduction of metal aerosols for the air-ICP and mercury-monitor CEM testing and for the introduction of $\mathrm{SO}_{2}$ and $\mathrm{HCl}$ gases during mercury-monitor testing. Sampling from the stack occurred on opposite sides of the same port, using one sampling probe for the air-ICP and mercury-monitor CEM systems and a second probe for RM-29 sampling.

\section{Reduced-Pressure Air-ICP and Multi-Frequency AOTF-Echelle Spectrometer CEM}

For the on-line detection of metals $(\mathrm{Be}, \mathrm{Cd}, \mathrm{Cr}$, and $\mathrm{Pb})$ using the reduced-pressure airICP and multi-frequency AOTF-echelle spectrometer during the FY00 test at DIAL, significantly different system performance was observed when the sampling system was connected to the stack compared to the non-stack-connected results. When the sampling system was not connected to the stack (during initial testing and calibration), the four metals $\mathrm{Be}, \mathrm{Cd}, \mathrm{Cr}$, and $\mathrm{Pb}$ were detected using the reduced-pressure air-ICP and AOTF-echelle system at levels corresponding to approximately 5, 40, 10, and $50 \mu \mathrm{g} / \mathrm{dscm}$, respectively. However, when the sampling system was connected to the stack during RM-29 sampling (with metals introduced into the stack at higher concentrations than the initial calibration detection limits), only Be was detected. Some of the difference in system performance is thought to result from the use of compromise ICP plasma conditions during some of the stack-sampling time periods. The 
majority of the difference, however, is believed to result from an increase in the plasma emission background that was not effectively removed from the emission signals for $\mathrm{Be}, \mathrm{Cd}, \mathrm{Cr}$, and $\mathrm{Pb}$ during stack sampling. In particular, the polarizers used with the quartz AOTF were not adequate to eliminate the elevated plasma emission background signal during stack sampling, which resulted in a significant degradation of the detection limits for $\mathrm{Be}, \mathrm{Cd}, \mathrm{Cr}$, and $\mathrm{Pb}$ during the test at DIAL.

In the AOTF-echelle spectrometer, the quartz AOTF is placed between crossed polarizers. $^{3,4}$ If the polarizers function properly, only light selected by the AOTF (which rotates the polarization of the selected wavelength component in order to pass through the crossed polarizers) reaches the echelle spectrometer and detector. The polarizers that were used during the test at DIAL were ineffective in completely blocking the plasma background emission. The polarizers used are designed to function well in the $200-400 \mathrm{~nm}$ wavelength range (in the ultraviolet, the region of the strongest emission lines for $\mathrm{Be}, \mathrm{Cd}, \mathrm{Cr}$, and $\mathrm{Pb}$ ), but not as well in the visible and near-infrared regions. As a result, plasma background optical emission in the visible and near-infrared "leaks" through these polarizers, increasing the detected background signal. This background is non-specific plasma emission, not selected by the AOTF, and not Be, $\mathrm{Cd}, \mathrm{Cr}$, and $\mathrm{Pb}$ emission lines. For the air-ICP (with the sampling system not connected to the stack), this plasma background is relatively small and manageable. However, with the sampling system connected to the stack, a significant increase in the background signal level occurred, as shown in Figure 6. This increase is thought to arise from the introduction of carbon-containing stack gas into the air-ICP, resulting in an increase in $\mathrm{CN}, \mathrm{CH}$, and other molecular band plasma emission features. This increase (and the associated noise on this background signal) is believed to have led to the degradation in the AOTF-echelle detection limits for $\mathrm{Be}, \mathrm{Cd}, \mathrm{Cr}$, and $\mathrm{Pb}$ when the reduced-pressure air-ICP sampling system was connected to the stack. 


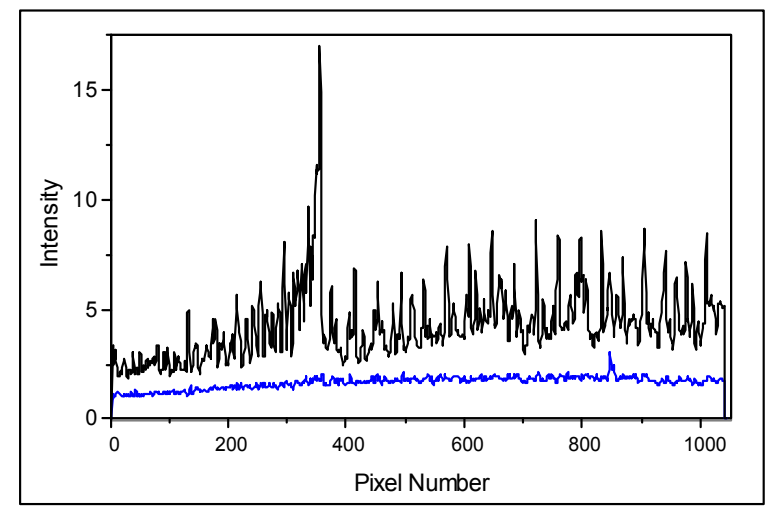

Figure 6. Air-ICP background emission spectra acquired using the multi-frequency AOTF-echelle spectrometer, with the sampling system connected to the stack (upper spectrum) and not connected (lower trace).

The difference in AOTF-echelle detection limits for $\mathrm{Be}, \mathrm{Cd}, \mathrm{Cr}$, and $\mathrm{Pb}$ with and without the sampling system connected to the stack is illustrated in Figure 7. These spectra were obtained by nebulizing solution standards containing $0,10,50$, and $100 \mathrm{ppm} \mathrm{Be}, \mathrm{Cd}, \mathrm{Cr}$, and $\mathrm{Pb}$ using the USN, with the metal aerosol output from the USN introduced into the continuous sampling system. The aerosol introduction point was a tee on the inlet side of the 12' Teflon sample line connected to the sampling chamber (see Figure 1). In Figure 7, the measured signal intensity is plotted as a function of time (point number), as the solution introduced into the USN was switched from water to $10 \mathrm{ppm}$ to $50 \mathrm{ppm}$ to $100 \mathrm{ppm}$ for the four metals, with the stack not connected (A-labeled traces). All four metals are detected at the 10-ppm solution concentration value, corresponding to approximately $140 \mu \mathrm{g} / \mathrm{dscm}$. With the sampling system connected to the stack, Be and $\mathrm{Cr}$ were detected (B-labeled traces) as 0, 100, 50, and $10 \mathrm{ppm}$ solutions were nebulized, but at a much lower signal-to-noise ratio. The elevation in the background signal (and the associated noise) resulted in $\mathrm{Cd}$ and $\mathrm{Pb}$ being undetectable, even at the 100-ppm solution concentration value, approximately $1400 \mu \mathrm{g} / \mathrm{dscm}$. It should be noted that a higher ICP RF power and a higher axial channel gas flow rate (approximately 1.7 compared to $1.3 \mathrm{Lpm}$ ) were used for the stack-connected data in Figure 7. These modified operating conditions were selected as compromise conditions thought to be necessary due to axial channel gas flow variations and the resulting ICP torch flicker observed during stack sampling on 9/21/00. (On prior days, no significant ICP flicker was observed during stack sampling; however, on these days, ICP torches that had partially-fused axial channels - less than the normal 1-mm diameter aperture - were used.) The plotted concentrations are the values measured using the initial 
calibration curves acquired on $9 / 19 / 00$, and the offset in concentration values shows differences in the background signal levels measured without and with the stack connected. The effect is most severe for $\mathrm{Cd}$ and $\mathrm{Pb}$, in part because the sensitivity for these two metals is lower than that for $\mathrm{Be}$ or $\mathrm{Cr}$. For these four metals, $\mathrm{Be}$ has the highest sensitivity, with $\mathrm{Cr}, \mathrm{Cd}$, and $\mathrm{Pb}$ approximately 3,14 , and 50 times less sensitive, based on the slopes of the initial calibration curves obtained during testing at DIAL. However, the relative positions of the plasma background emission peaks (in Figure 6) with respect to the analyte line pixel positions also affects the severity of the effect observed, with the stack connected.
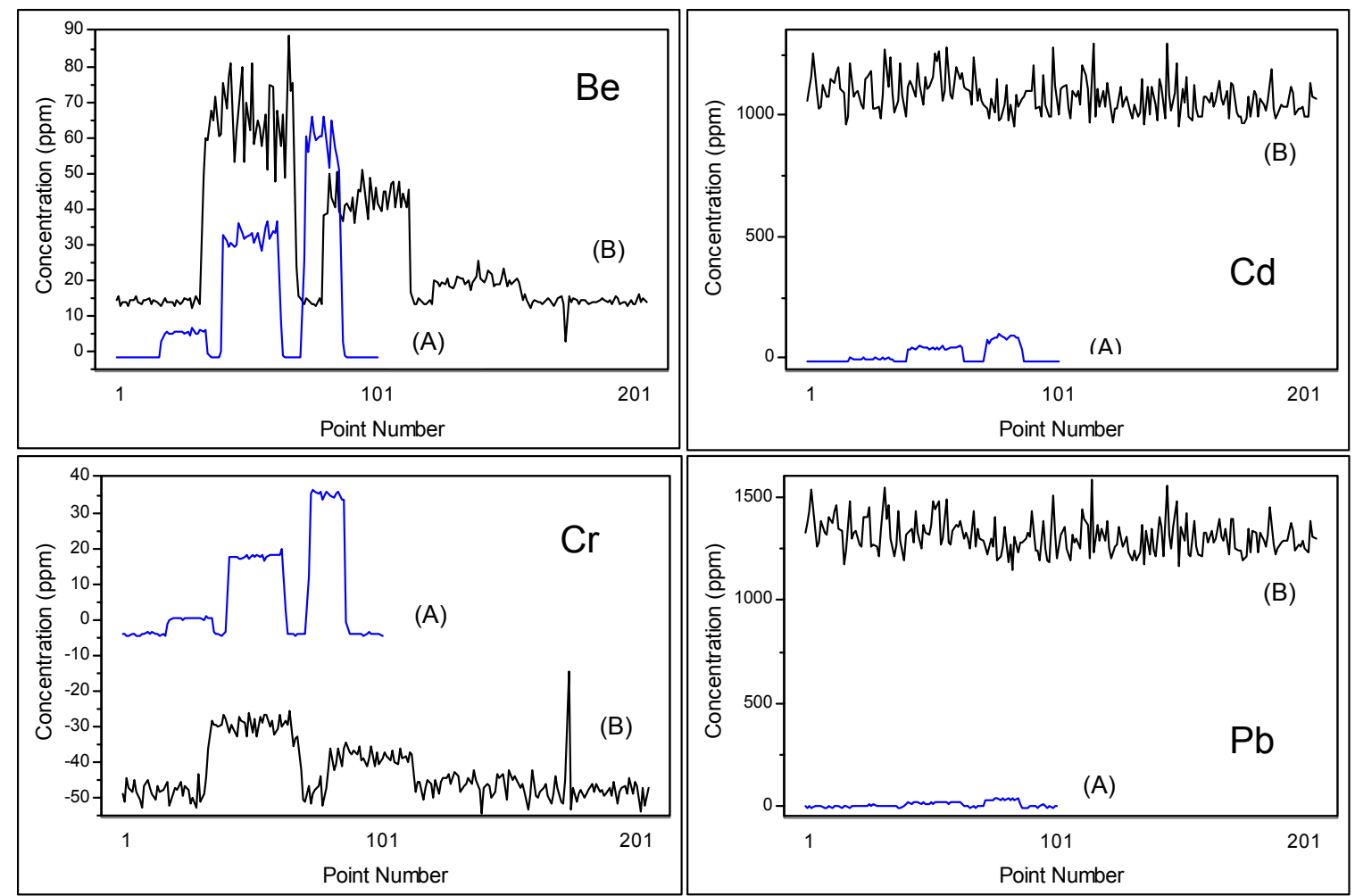

Figure 7. Air-ICP monitor data for Be (II) 313.04-nm, Cd (I) 228.80-nm, Pb (I) 405.78-nm, and Cr (I) 357.87-nm lines (clockwise, from upper left) acquired using the AOTF-echelle spectrometer, with metals spiked into the continuous sampling system at the front of the 12' Teflon sample line. The A-labeled traces are signals detected without the stack connected, resulting from the introduction of $0,10,50$, and $100 \mathrm{ppm}$ solutions using the USN. The B-labeled traces are signals detected with the stack connected, introducing $0,100,50$, and $10 \mathrm{ppm}$ solutions into the USN.

As mentioned above, only beryllium was detected using the reduced-pressure air-ICP and multi-frequency AOTF-echelle spectrometer system during RM-29 sampling. An example of the monitor data acquired is shown in Figure 8 for the Be (II) 313.04-nm line, for the time periods prior to and during RM-29 sampling on 9/21/00. For this particular run, water was initially spiked into the stack (USN output aerosol introduced into the stack at the port indicated in Figure 
5), followed by the multi-metals standard, water, the multi-metals standard (for a period of time slightly longer than the 1-hour RM-29 sampling), and then water (at the end of the monitoring period). For Figure 8, the measured Be concentrations have been converted to $\mu \mathrm{g} / \mathrm{dscm}$ values using the USN efficiency measured prior to the test (16\%), the solution delivery rate (2.6 $\mathrm{mL} / \mathrm{min})$, the stack-gas flow rate $\left(4.1 \mathrm{~m}^{3} / \mathrm{min}\right)$, and the moisture content $(11.7 \%$ for this run). A correction factor for the measured daily response of the air-ICP AOTF-echelle system (signal intensity measured compared to that for the initial calibration curves) has also been applied. The initial monitor data in Figure 8 was acquired at a rate of approximately ten points per minute; starting at point number 312 , a scan-averaged data acquisition of approximately two points per minute was used, resulting in an improved signal-to-noise ratio. The measured Be aerosol concentration during RM-29 sampling for this run was $145 \mu \mathrm{g} / \mathrm{dscm}$ initially (points 180-311) and $161 \mu \mathrm{g} / \mathrm{dscm}$ at the end of the run (points 312-414). Because of the shift in the baseline over the course of this run, baseline-average values of 49 and $81 \mu \mathrm{g} / \mathrm{dscm}$, respectively, have been subtracted from the initial and final Be aerosol concentrations.

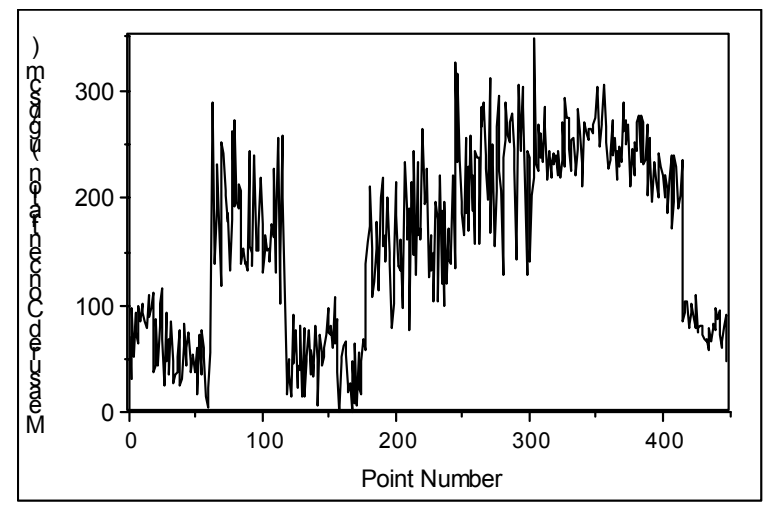

Figure 8. Air-ICP monitor data for beryllium using the Be (II) 313.04-nm line, during RM-29 sampling on $9 / 21 / 00$; see text for discussion.

The measured air-ICP CEM results for Be and the determined RM-29 aerosol concentrations are listed in the table below. These air-ICP Be concentrations are based on an estimated efficiency for the USN used to calibrate the response of the air-ICP system. Prior to the test at DIAL, the nebulizer efficiency was measured under normal operating conditions, and a value of $16 \%$ was obtained. However, during the testing at DIAL, modified USN operating conditions were used - higher concentration solutions were nebulized and an extended length of tubing was used as the USN aerosol output line. We have no exact calibration of the USN under these conditions. However, air-ICP monitor data acquired during the test indicated that aerosol 
concentrations approximately 2.5 times lower resulted from the use of the extended length of USN output tubing. Based on the solution concentration used to deliver metals to the stack and the RM-29 results for those metals, one calculates an effective nebulizer efficiency of 5.3\% when connected to the stack, about three times lower than the $16 \%$ value measured prior to the test. Unfortunately, we did not have the opportunity to recalibrate the nebulizer under the conditions that it was used as the calibration source. As a result, the $5.3 \%$ effective efficiency was used to calculate the air-ICP Be concentrations below, along with the known solution delivery rate, stack-gas flow rate and moisture content, and the measured daily air-ICP response factor. The first two runs were conducted on one day $(9 / 20 / 00)$, and the reason for the discrepancy in the measured air-ICP Be values for run 2 (12 compared to $77 \mu \mathrm{g} / \mathrm{dscm}$ ) is unknown. The third run was conducted on the following day, and a value of $51 \mu \mathrm{g} / \mathrm{dscm}$ Be was determined. Since the concentration of the four metals in the multi-metals standard solution nebulized was the same for a given run, one would expect the RM-29 measured values for $\mathrm{Be}, \mathrm{Cd}$, and $\mathrm{Pb}$ to be the same. (Measured $\mathrm{Cr}$ concentrations are routinely elevated due to background $\mathrm{Cr}$ detected from the stack, perhaps due to corrosion of some steel components in the stack.) For run 1, the average $\mathrm{RM}-29 \mathrm{Be}-\mathrm{Cd}-\mathrm{Pb}$ aerosol concentration is $106.7 \mu \mathrm{g} / \mathrm{dscm}$. For run 2, significantly lower values were determined (average Be-Cd-Pb concentration of $80.8 \mu \mathrm{g} / \mathrm{dscm}$ ), although this run was nominally a repeat of run 1. Lower aerosol concentrations are expected for run 3 (measured average $\mathrm{Be}-\mathrm{Cd}-\mathrm{Pb}$ concentration of $75.3 \mu \mathrm{g} / \mathrm{dscm}$ ), since a slightly lower concentration multimetals standard was nebulized using the USN. The 5.3\% nebulizer efficiency used to calculate the tabulated air-ICP Be concentrations may be a conservative value; this is an effective efficiency that may include some aerosol losses in the stack in the five meters between the sample introduction and sample extraction ports. The air-ICP system was calibrated introducing the USN aerosol at a tee between the 24' and 12' sample lines (not into the stack), so it is conceivable that a slightly higher effective efficiency resulted during calibration of the air-ICP. If one assumes that the air-ICP and RM-29 values for Be should be the same for run 1, then the effective efficiency for the nebulizer (non-stack-connected) is about 7.4\%. Applying this value to run 3 gives a Be value of $71.2 \mu \mathrm{g} / \mathrm{dscm}$, in reasonably good agreement with the RM-29 value, $67.9 \mu \mathrm{g} / \mathrm{dscm}$. The air-ICP data for Be for run 2 is problematic; the reason for the lower value is unknown. 
Measured Multi-Metals Aerosol Concentrations ( $\mu \mathrm{g} / \mathrm{dscm})$

\begin{tabular}{|c|c|c|c|c|}
\hline \multirow{2}{*}{\multicolumn{2}{|c|}{ Air-ICP CEM }} & Run 1 & Run 2 & Run 3 \\
\hline & & & & \\
\hline & $\mathrm{Be}$ & 77 & 12 & 51 \\
\hline \multirow[t]{5}{*}{$\underline{\mathrm{RM}-29}$} & & & & \\
\hline & $\mathrm{Be}$ & 106.4 & 84.9 & 67.9 \\
\hline & $\mathrm{Cd}$ & 104.5 & 71 & 75.2 \\
\hline & $\mathrm{Cr}$ & 167.5 & 153.1 & 145.5 \\
\hline & $\mathrm{Pb}$ & 109.2 & 86.6 & 82.9 \\
\hline
\end{tabular}

\section{Mercury-Monitor CEM}

Stability and reproducibility studies for the mercury-monitor CEM were performed at Ames Laboratory prior to the DIAL facility test. The experimental setup was similar to that described for the facility test except that no sampling chamber was used and the mercury/room air sample was pumped through the mercury-monitor CEM using the internal pump of the VICI Dynacalibrator. The sample gas flow rate used in these studies was the same as that for the DIAL test, one standard Lpm. Reproducibility studies were conducted by recording the response of the mercury monitor over a two-week period while introducing mercury vapor into the $1-\mathrm{m}$ absorption cell from a permeation tube having a certified emission rate of $8.71 \mathrm{ng} / \mathrm{min} \mathrm{Hg}$. Over the two-week period, the mercury-monitor CEM system yielded a response of 12.1 milliabsorbance units ( $\pm 3 \%$ ), after correction for any baseline drift. From this data, the detection limit of the mercury-monitor CEM system was estimated to be $0.51 \mu \mathrm{g} / \mathrm{m}^{3} \mathrm{Hg}$. (Throughout this section, the reported mercury concentration is the average plus or minus one standard deviation.)

Isokinetic sampling for the mercury-monitor CEM testing at DIAL was performed in the same manner and from the same stack location as that for the reduced-pressure air-ICP CEM tests. The response of the mercury monitor was tested at a low level of $8 \mu \mathrm{g} / \mathrm{m}^{3}$ and a high level of $80 \mu \mathrm{g} / \mathrm{m}^{3}$ in the presence of hydrogen chloride $(\mathrm{HCl})$ and sulfur dioxide $\left(\mathrm{SO}_{2}\right)$, common interferents present in combustion stacks. The absorption cell was heated to a temperature of $125^{\circ} \mathrm{C}$ to prevent condensation of moisture. The temperature measured at the cell windows was $69^{\circ} \mathrm{C}$, well above the dew-point temperature of the DIAL stack gas.

Facility testing of the mercury monitor was conducted over a two-day period. The first day of testing involved introducing mercury at high levels $\left(80 \mu \mathrm{g} / \mathrm{m}^{3}\right)$ in the presence of approximately $100 \mathrm{ppmV} \mathrm{HCl}$ and $50 \mathrm{ppmV} \mathrm{SO}_{2}$. Figure 9 shows typical data acquired during 
the high-level run during RM-29 sampling on the first day. The $\mathrm{SO}_{2}$-corrected average concentration for mercury was $27.3( \pm 0.93) \mu \mathrm{g} / \mathrm{m}^{3}$ for this particular run. For this test, $\mathrm{SO}_{2}$ was continually introduced at approximately $50 \mathrm{ppmV}$. The arrows in Figure 9 indicate when $\mathrm{HCl}$ gas was introduced into the stack combustion stream. As can be noted from the data in Figure 9, the introduction of $\mathrm{HCl}$ did not result in any significant change in the measured mercury concentration. It is presumed that any mercuric chloride that formed in the stack under these conditions was subsequently decomposed in the pyrolyzer into elemental mercury and chlorine gas prior to passing through the absorption cell.

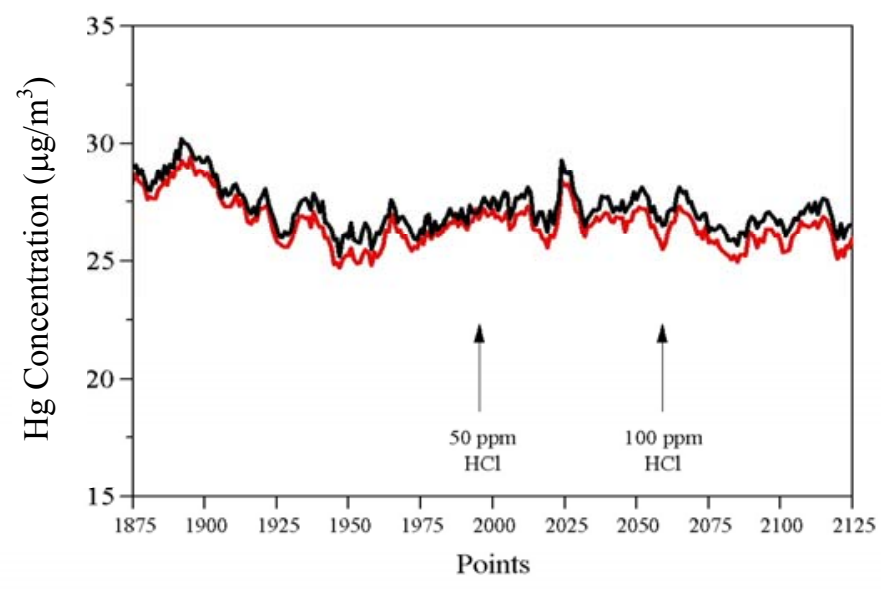

Figure 9. Mercury-monitor CEM data measured for high $\mathrm{Hg}$ concentration $\left(80 \mu \mathrm{g} / \mathrm{m}^{3}\right)$ in the DIAL stack, when $\mathrm{HCl}$ was introduced at approximately 50 and $100 \mathrm{ppmV} \mathrm{HCl}$ (indicated by the arrows). The top trace is the $\mathrm{SO}_{2}$-uncorrected mercury concentration, and the bottom trace is the $\mathrm{SO}_{2}$-corrected value. The $\mathrm{SO}_{2}$ concentration for this run was approximately $50 \mathrm{ppmV}$.

Although the measured mercury concentration was lower than the expected $80 \mu \mathrm{g} / \mathrm{m}^{3}$ value, the determined values were fairly stable. The lower-than-expected measured value is believed to be due to a loose fitting on the sampling chamber that resulted in a dilution of the stack sample gas with room air. This leak was not discovered until the middle of the second day of the mercury-monitor CEM testing. Once the loose fitting was discovered and the leak was sealed, the measured $\mathrm{Hg}$ concentrations reached the values expected, as discussed below. As a result, only the mercury-monitor data obtained after the discovery of the leak will be compared to the RM-29 results.

The second day of testing involved monitoring mercury at low levels $\left(8 \mu \mathrm{g} / \mathrm{m}^{3}\right)$ in the presence of approximately $25 \mathrm{ppmV} \mathrm{HCl}$ and $500 \mathrm{ppmV} \mathrm{SO}_{2}$. Figure 10 shows the effect of $\mathrm{SO}_{2}$ at low mercury levels. This data was acquired prior to the discovery of the sampling chamber 
gas leak, so the measured values are lower than the expected Hg stack concentration. This data was obtained with $\mathrm{HCl}$ present at $25 \mathrm{ppmV}$. Prior to the introduction of $\mathrm{SO}_{2}$, the measured mercury concentration was $1.51( \pm 0.21) \mu \mathrm{g} / \mathrm{m}^{3}$. It is important to note that the $\mathrm{SO}_{2}$-corrected and -uncorrected values are identical at this point. At approximately point $970, \mathrm{SO}_{2}$ was starting to be detected by the mercury-monitor CEM, as indicated by the increase in the measured $\mathrm{SO}_{2}$ and uncorrected mercury concentrations. Sulfur dioxide was initially introduced at a level of approximately $250 \mathrm{ppmV}$. At this level, the corrected mercury concentration was $0.98( \pm 0.25)$ $\mu \mathrm{g} / \mathrm{m}^{3}$. The $\mathrm{SO}_{2}$ level was then further increased to $500 \mathrm{ppmV}$, at about point number $1030 \mathrm{in}$ Figure 10. At this $\mathrm{SO}_{2}$ level, the corrected mercury concentration was $0.58( \pm 0.25) \mu \mathrm{g} / \mathrm{m}^{3}$. From this data, it would appear that the $\mathrm{SO}_{2}$-correction algorithm used was slightly over-correcting for the amount of $\mathrm{SO}_{2}$ present in the gas sample stream.

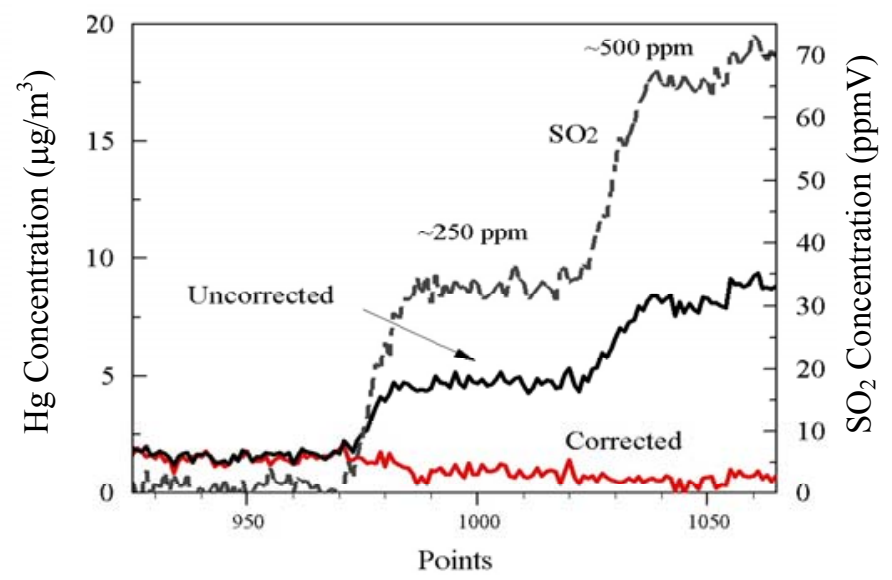

Figure 10. Mercury-monitor CEM data at low $\mathrm{Hg}$ concentration $\left(8 \mu \mathrm{g} / \mathrm{m}^{3}\right)$ in the DIAL stack. The dark solid line is the $\mathrm{SO}_{2}$-uncorrected mercury concentration, and the lighter solid trace is the value after being corrected for $\mathrm{SO}_{2}$. The dashed line indicates the measured $\mathrm{SO}_{2}$ concentration. The measured $\mathrm{SO}_{2}$ values, approximately 35 and $70 \mathrm{ppmV}$, are lower than the expected levels, 250 and $500 \mathrm{ppmV}$, due to dilution in the sampling chamber because of the chamber gas leak.

After the problem with the loose fitting on the sampling chamber was discovered and corrected, mercury concentrations closer to the expected values were measured, as shown in Figure 11, a re-run of the high-level stack mercury concentration $\left(80 \mu \mathrm{g} / \mathrm{m}^{3}\right)$ on the second day of testing. Sealing the leak in the sampling chamber fitting also induced a baseline rise in the absorption measurement, as indicated in Figure 11 by the difference between the room air zerocheck (points 0-15, approximately) and stack gas (points 15-90) baseline values, prior to the introduction of $\mathrm{Hg}$ into the stack. It is believed the baseline increase is most likely due to the 
increase of moisture in the absorption cell (i.e., the stack gas sample was no longer being diluted with drier room air), although other interferents potentially present in the stack gas (nitrogen dioxide or organic species) may also contribute. Although the baseline increase was undesirable, once stabilized, it did not present any problems in taking measurements. In order to account for the change in the baseline, an extrapolated baseline was generated and a point-by-point correction was applied to yield the mercury concentration in the combustion stack, for both the $\mathrm{SO}_{2}$-corrected and $\mathrm{SO}_{2}$-uncorrected data in Figures 11 and 12. When mercury was introduced into the stack (approximately points 90-300 in Figure 11), the measured $\mathrm{SO}_{2}$-corrected mercury concentration was $78.4( \pm 3.0) \mu \mathrm{g} / \mathrm{m}^{3}$. The $\mathrm{SO}_{2}$-uncorrected mercury-monitor data yielded a value of $77.8( \pm 2.9) \mu \mathrm{g} / \mathrm{m}^{3}$ mercury for the 10-minute testing period shown in Figure 11. The measured $\mathrm{SO}_{2}$ concentration was $674( \pm 4.4) \mathrm{ppmV}$, higher than the expected $500 \mathrm{ppmV}$ value. While it is possible that there is a low (background) concentration of $\mathrm{SO}_{2}$ in the combustion stack gas at DIAL, the higher-than-expected measured $\mathrm{SO}_{2}$ concentration may also be due to absorption at 313.18-nm by water vapor or other stack gas interferents.

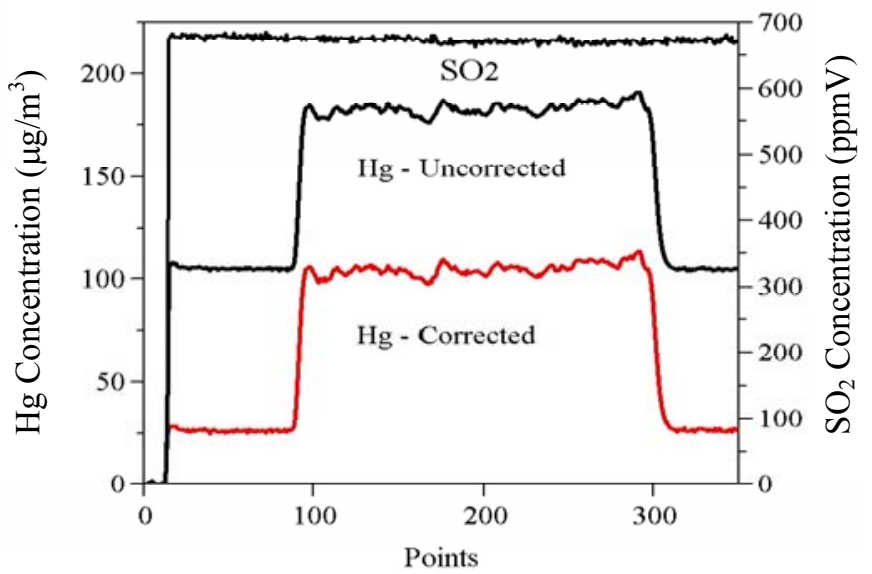

Figure 11. Repeat of a high-level $\left(80 \mu \mathrm{g} / \mathrm{m}^{3}\right)$ mercury run after sealing the leak in the sampling chamber on the second day of $\mathrm{Hg}$ stack monitoring. The increased baseline for the mercury-monitor data is likely due to an increase in the absorption contribution of water at $253.65-\mathrm{nm}$ measured for the stack gas sample compared to that for room air.

Figure 12 shows the response of the mercury monitor during a low-level $\left(8 \mu \mathrm{g} / \mathrm{m}^{3}\right)$ run on the second day of testing, in the presence of approximately $500 \mathrm{ppmV} \mathrm{SO}_{2}$ and $25 \mathrm{ppmV} \mathrm{HCl}$. Again, a baseline offset between the room air zero-check and stack gas values (points 0-100 in Figure 12, prior to the introduction of $\mathrm{Hg}$ ) is observed. This increase is most likely due to the increase in moisture for the stack gas sample compared to that for room air. For the two-hour 
testing period shown in Figure 12, the measured $\mathrm{SO}_{2}$-corrected mercury concentration is 11.8 $( \pm 1.2) \mu \mathrm{g} / \mathrm{m}^{3}$. The $\mathrm{SO}_{2}$-uncorrected data yields a mercury concentration of $11.2( \pm 1.4) \mu \mathrm{g} / \mathrm{m}^{3}$. Some of the variance in these determined values is due to the baseline drift observed over the course of this two-hour run. The source of this drift in the measured values for this mercurymonitor data is unknown.

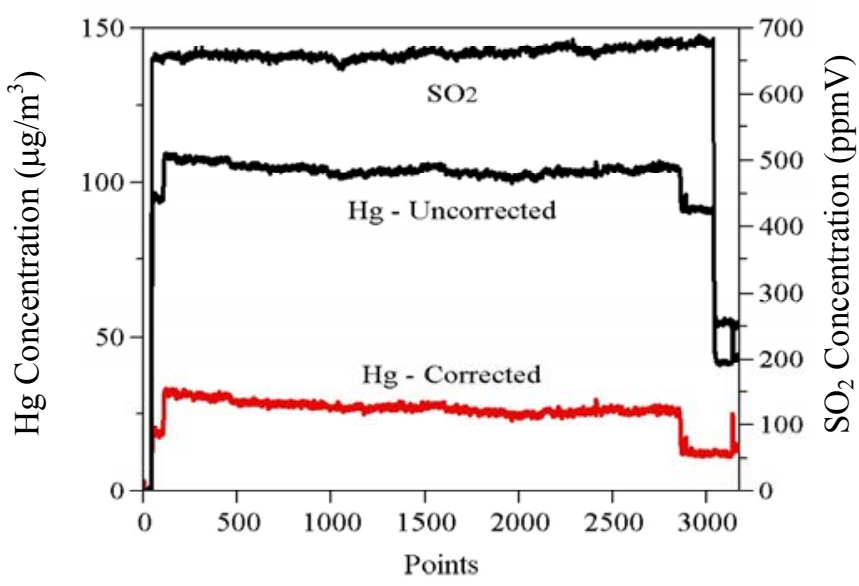

Figure 12. Low-level $\left(8 \mu \mathrm{g} / \mathrm{m}^{3}\right)$ mercury test run, in the presence of approximately $25 \mathrm{ppmV} \mathrm{HCl}$ and $500 \mathrm{ppmV} \mathrm{SO}_{2}$. The baseline increase is likely due to the absorption contribution of water at $253.65-\mathrm{nm}$ measured for the stack gas compared to that for room air. The measured $\mathrm{SO}_{2}$ concentration is $674( \pm 4.4)$ ppmV.

The test results for the mercury-monitor CEM and RM-29 sampling are summarized in the table below. Only the mercury CEM concentrations determined during the latter part of the second day are reported (the values measured after correcting the sampling chamber leak). The RM-29 and mercury CEM results are compared as micrograms Hg per dry standard cubic meter, with the percent water in the sample stream determined from the RM-29 sampling procedure. Although only one measurement for the mercury-monitor CEM is reported for each of the highand low-level mercury tests at DIAL, the values are in very good agreement with the RM-29 results.

\begin{tabular}{crr|rr} 
& \multicolumn{2}{c|}{ Day 1} & \multicolumn{2}{c}{ Day 2} \\
\cline { 2 - 5 } RM-29 & $89.42 \mu \mathrm{g} / \mathrm{dscm}$ & $86.00 \mu \mathrm{g} / \mathrm{dscm}$ & $9.92 \mu \mathrm{g} / \mathrm{dscm}$ & $12.52 \mu \mathrm{g} / \mathrm{dscm}$ \\
$\mathrm{H}_{2} \mathrm{O}$ & $11.46 \%$ & $11.21 \%$ & $10.86 \%$ & $10.82 \%$ \\
Mercury CEM Concentration & $* 78.4( \pm 3.0) \mu \mathrm{g} / \mathrm{m}^{3}$ & - & $11.8( \pm 1.2) \mu \mathrm{g} / \mathrm{m}^{3}$ \\
\cline { 2 - 5 } Mercury CEM- $\mathrm{H}_{2} \mathrm{O}$ Corrected & $* 87.9( \pm 3.4) \mu \mathrm{g} / \mathrm{dscm}$ & - & $13.2( \pm 1.3) \mu \mathrm{g} / \mathrm{dscm}$
\end{tabular}

* Data taken on day 2 of mercury-monitor testing, using the same operating conditions as those used on day 1. 


\section{Conclusions and Continued Work}

The work performed during the site-test at DIAL at the end of FY00 was the first fieldtest of both the multi-frequency AOTF-echelle spectrometer and the mercury-monitor CEM systems. A significant amount of information was obtained during the tests, regarding the performance of the reduced-pressure air-ICP and mercury-monitor CEM systems in nonlaboratory operating conditions. As with any initial field-test, successful results were obtained for some aspects of the test, some problems were identified, and some changes and modifications to the instrumentation and operating procedures will be made based on the results of the work done at DIAL.

For the reduced-pressure air-ICP and multi-frequency AOTF-echelle spectrometer, used as a multi-metals CEM system, the most significant problem was the degradation in detection limits for $\mathrm{Be}, \mathrm{Cd}, \mathrm{Cr}$, and $\mathrm{Pb}$ during stack sampling that resulted from the elevation in the detected plasma background emission. Since the test at DIAL, the $\alpha$-BBO Glan-Taylor polarizers have been replaced with $\alpha$-BBO Rochon prism polarizers (Casix model PRH8010). The new polarizers function well from $200-1000 \mathrm{~nm}$, significantly reducing the amount of visible and near-infrared plasma background signal that "leaks" through the polarizers (compared to the Glan-Taylor polarizers). With the incorporation of these new polarizers into the optics of the AOTF-echelle, the performance of the spectrometer is improved considerably. A small amount of non-AOTF-selected plasma background is still detected (possibly due to the birefringence of the AOTF crystal itself or scattering from the AOTF), but the situation is significantly improved with the new Rochon polarizers compared to the Glan-Taylor polarizers used during the test at DIAL.

Despite the incorporation of the ballast into the continuous sampling system during FY00, apparent air-ICP axial channel gas flow fluctuations and resulting ICP torch flicker were observed during testing when an ICP torch having a 1-mm diameter axial channel was used. The inclusion of the ballast has not resulted in a completely stable sample gas flow to the reducedpressure air-ICP, at least when sampling from a reduced-pressure exhaust stack such as that at DIAL, using the sampling pump and the ICP chamber pump. However, during times that partially-fused $(<1-\mathrm{mm})$ axial channel ICP torches were used, no obvious torch flicker or significant axial channel gas flow variations were observed. In addition, no significant gas flow fluctuations were observed during testing of the mercury-monitor CEM system using the same 
sampling system (with a different pump to draw 1 standard Lpm through the 1-m absorption cell). Therefore, the exact reason for the observed air-ICP axial channel gas flow fluctuations is not entirely clear at this point.

Encouraging results were obtained for the mercury-monitor CEM system, once the problem with the loose fitting on the sampling chamber was discovered and corrected. The mercury concentrations measured using the mercury-monitor CEM on the second day of testing agreed very well the RM-29 determined values. Introduction of $\mathrm{SO}_{2}$ into the exhaust gas stream did not adversely affect the performance of the mercury-monitor CEM, since an $\mathrm{SO}_{2}$-correction algorithm was incorporated into the data acquisition software and since the design of the system allows for the $\mathrm{SO}_{2}$ concentration to be measured concurrently with the mercury concentration during stack sampling. Introduction of $\mathrm{HCl}$ into the exhaust gas stream also did not obviously affect the performance of the mercury-monitor CEM. This means that either a very small concentration of oxidized mercury compounds were formed under the stack-operating conditions during the test or that the pyrolysis system incorporated into the mercury-monitor CEM effectively converts oxidized mercury to elemental mercury, prior to analysis.

During testing at DIAL, the potential need for incorporating water- and nitrogen dioxidecorrection algorithms and procedures (similar to that done for $\mathrm{SO}_{2}$ ) into the mercury-monitor CEM system became evident. Laboratory experiments are being conducted to determine the possibility of performing on-line water vapor and $\mathrm{NO}_{2}$ interference corrections to the measured mercury absorption, to eliminate or mitigate the baseline increase measured during the second day of mercury-monitor testing. Some changes in the operation of the mercury-monitor CEM system will likely be made as a result of the testing at DIAL. One of these is the more frequent utilization of the VICI Dynacalibrator. Instead of simply doing a zero-check, the response of the mercury-monitor CEM will be determined by introducing mercury vapor from the Dynacalibrator into the system and measuring the mercury concentration after doing a zerocheck. (This was initially attempted at DIAL, but due to experimental difficulties in introducing the Dynacalibrator output gas into the continuous sampling system, was not done throughout the course of mercury-monitor testing.) This procedure should provide additional information on the response of the mercury CEM over the course of the testing period, to determine whether changes in measured mercury concentrations are due to instrumental drift or result from actual changes in stack-mercury levels or stack-operating conditions. Another change will be the 
integration of a pyrolyzer bypass line, allowing for the sequential analysis of elemental mercury in the gas sample stream (bypassing the pyrolyzer) and total mercury (utilizing the pyrolyzer).

The mercury-monitor CEM system, with modifications resulting from the testing done at DIAL, will be tested at a DOE or EPA site during FY01.

\section{Acknowledgments}

Ames Laboratory is operated for the U.S. Department of Energy by Iowa State University, under contract number W-7405-Eng-82. This work was supported by the U.S. Department of Energy, Office of Environmental Management, Office of Science and Technology, through the Mixed Waste Focus Area. The authors thank R. Arun Kumar, John Etheridge, Jay McCown, Andy Hodnett, Pete Herring, and Jerry Jones for their efforts in performing the work necessary to allow operation of the combustion test-stand at DIAL, Walter Okhuysen for performing stack LDV measurements, and David Hairston and Donna Rogers for performing RM-29 sampling during the test. The authors also thank Glenn Norton at Ames Laboratory for his involvement in the initial setup and laboratory testing of the mercury-monitor CEM system.

\section{References}

1. Code of Federal Regulations, Part 60, Appendix A (61 FR 18262 4/25/96).

2. D. P. Baldwin, D. S. Zamzow, D. E. Eckels, G. P. Miller, R. Wiser, and S. Tao, "Testing of a Continuous Sampling Air-ICP System as a Continuous Emission Monitor at the Diagnostic Instrumentation and Analysis Laboratory, September 12-17, 1999," Ames Laboratory Report IS-5138, October, 1999.

3. D. P. Baldwin, D. S. Zamzow, D. E. Eckels, and G. P. Miller, "A Continuous Sampling AirICP for Metals Emission Monitoring," in Environmental Monitoring and Remediation Technologies II, T. Vo-Dinh and R. L. Spellicy (Eds.), Proceedings of SPIE Vol. 3853, pp. 213-220, 1999.

4. D. P. Baldwin, D. S. Zamzow, D. E. Eckels, and G. P. Miller, "AOTF-Echelle Spectrometer for Air-ICP-AES Continuous Emission Monitoring of Heavy Metals and Actinides," in Environmental Monitoring and Remediation Technologies, T. Vo-Dinh and R. L. Spellicy (Eds.), Proceedings of SPIE Vol. 3534, pp. 478-486, 1999.

5. Mercury in the Environment: Proceedings of a Specialty Conference, VIP-91, published by the Air \& Waste Management Association, Sewickley, PA, 1999. Session 11 - Mercury Measurement, pp. 339-409.

6. J. Y. Lu, W. H. Schroeder, T. Berg, J. Munthe, D. Schneeberger, and F. Schaedlich, "A Device for Sampling and Determination of Total Particulate Mercury in Ambient Air," Anal. Chem., 70, pp. 2403-2408, 1998. 